\title{
Comparison between low-cost and traditional MEMS accelerometers: a case study from the M7.1 Darfield, New Zealand, aftershock deployment
}

\author{
Elizabeth S. Cochran ${ }^{1,}$, Jesse F. Lawrence ${ }^{2}$, Anna Kaiser ${ }^{3}$, Bill Fry $^{3}$, Angela Chung ${ }^{2}$, Carl Christensen ${ }^{2}$
}

\author{
${ }^{1}$ University of California, Department of Earth Sciences, Riverside, CA, USA \\ 2 Stanford University, Geophysics Department, Stanford, CA, USA \\ ${ }^{3}$ GNS Science, Natural Hazards Division, Lower Hutt, New Zealand
}

\author{
Article history \\ Received June 29, 2011; accepted October 25, 2011. \\ Subject classification: \\ Seismology instruments and techniques, Ground motion, Seismic risk, Seismological data, Citizen science.
}

\begin{abstract}
Recent advances in micro-electro-mechanical systems (MEMS) sensing and distributed computing techniques have enabled the development of low-cost, rapidly deployed dense seismic networks. The Quake-Catcher Network (QCN) uses triaxial MEMS accelerometers installed in homes and businesses to record moderate to large earthquakes. Real-time accelerations are monitored and information is transferred to a central server using open-source, distributed computing software installed on participating computers. Following the September 3, 2010, $M_{w} 7.1$ Darfield, New Zealand, earthquake, 192 QCN stations were installed in a dense array in the city of Christchurch and the surrounding region to record the on-going aftershock sequence. Here, we compare the ground motions recorded by QCN accelerometers with GeoNet strong-motion instruments to verify whether low-cost MEMS accelerometers can provide reliable ground-motion information in network-scale deployments. We find that observed PGA and PGV amplitudes and RMS scatter are comparable between the GeoNet and QCN observations. Closely spaced stations provide similar acceleration, velocity, and displacement time series and computed response spectra are also highly correlated, with correlation coefficients above 0.94 .
\end{abstract}

\section{Introduction}

While many seismological and engineering applications would benefit from very dense strong-motion observations, the costs of deploying and maintaining dense seismic networks has limited their implementation. However, recent improvements in micro-electro-mechanical systems (MEMS) sensor technology as well as development of new communication and processing techniques can greatly reduce per-station costs. Over the past decade, several studies have shown that low-cost triaxial MEMS accelerometers provide sufficient sensitivity levels and reliability for use in geophysical and earthquake engineering applications [e.g.
Holland 2003, Evans et al. 2005, Hons et al. 2008, Zhao and Xiong 2009]. Furthermore, infrastructure costs can be reduced by transferring data over existing wireless networks [e.g. Evans et al. 2005, Fleming et al. 2009, Picozzi et al. 2009] or even by taking advantage of underutilized personal computers for monitoring sensors and initial data processing [e.g. Cochran et al. 2009a].

One such effort to develop a low-cost strong-motion network is the Quake-Catcher Network (QCN), which uses MEMS accelerometers either internal to laptops or connected via USB to desktop computers [e.g. Cochran et al. 2009a, Cochran et al. 2009b, Chung et al. 2011]. QCN utilizes data from triaxial MEMS accelerometers of varying resolution (currently 8-14 bit) that cost less than US\$50 per sensor. QCN runs on the Berkeley Open Infrastructure for Network Computing (BOINC) open-source platform [Anderson 2004]. BOINC enables scientists to create a distributed computing project to which a volunteer participant can donate their unused central processing unit time. The QCN station hardware includes a MEMS sensor connected via USB-port to a computer or a sensor internal to a laptop; however, no datalogger or GPS unit is used. This data collection scheme greatly reduces the cost of installing an individual seismic station.

The MEMS sensor is monitored through BOINC software that is installed on a participant's computer and communicates with the central QCN server. Timing and station location must be determined without a local GPS unit. We utilize Network Time Protocol (NTP; http: / / www. ntp.org) [Mills 1990, Frassetto et al. 2003] to ensure accurate timing at each station. Each station requests a timing ping from the server every 15 minutes and internally tracks the timing drift. The offset (in seconds) between the internal 
computer clock and NTP time is used to correct the data. Frassetto et al. [2003] showed that NTP accuracy is typically within $+/-20 \mathrm{msec}$, with only 9 out of approximately 17,000 clock locks having errors larger than 0.1 seconds. A qualitative comparison of timing at nearby $\mathrm{QCN}$ and GeoNet stations as well as the observed moveouts across the network suggests adequate timing control on most stations. However, we noted a few stations $(<5)$ that had consistently poor timing control (arrivals were several seconds early or late). In these cases, the individual computer's network settings may be affecting the NTP pings, but further analysis is required to verify the source of these timing errors.

A station's location is determined using either an IP look-up table or via participant entry into a Google Maps Application Programming Interface (API). We get an initial, low-resolution station location using the IP lookup table, which utilizes the computers IP address to estimate the station location. This location method is $83 \%$ accurate to within $40 \mathrm{~km}$ in urban areas, but location errors can be much larger $(>100 \mathrm{~km})$ especially if the participant logs into a VPN account (http://www.maxmind.com). To improve the station location accuracy, participants can enter their location via a Google Maps API during the initial software installation. Participants are directed to a Google Maps that is centered on the best estimate of their location from the IP lookup. Participants then mark their location on the map and can achieve a location that is accurate to sub-building scale if they utilize the 'satellite' view. The location type, either IP or user-input, is included in the station's metadata. During installation the three components of the sensor are aligned North-South, East-West and Vertical; the orientation, if known, is also recorded in the metadata. Teams from QCN and GNS Science installed most of the stations used here, so over $95 \%$ of the stations had locations entered using the Google Maps API and sensors aligned to North.

Each station monitors the sensor accelerations in realtime and produces both triggers and waveform records. A trigger is generated when the current acceleration is significantly larger than the previous 60 seconds of acceleration, as determined by a modified short-term average/ long-term average (STA/LTA) algorithm [Cochran et al. 2009a, 2009b]. When a trigger occurs, a minimal amount of information is rapidly transferred to the central server [Chung et al. 2011]. Waveforms are collected in either triggered mode or continuous mode. In triggered mode, 180 seconds of time-series data are saved around the trigger time, with a 60 second pre-trigger window and a 120 second posttrigger window. Triggered waveforms are only uploaded to the server if correlated with an earthquake reported by the U.S. Geological Survey National Earthquake Information Center (NEIC) catalog (http: / / earthquake.usgs.gov) or by the QCN event detection algorithm [Chung et al. 2011]. In continuous mode, ten-minute-long records are transferred to the server when the QCN monitoring software is running. All time series data are recorded at 50 samples per second. New Zealand aftershock data were recorded in continuous mode.

Data collected by QCN may be used to augment existing seismic networks, essentially filling in the gaps between higher-quality sensors [e.g. Evans et al. 2005]. These data may provide valuable observations for use in practical applications such as earthquake early warning as well as seismic hazard mapping and analysis. For example, increasing station density may reduce the time needed to detect and characterize an earthquake, potentially providing a few critical extra seconds of warning to mitigate the effects of damaging ground motion [Kanamori 2005]. Chung et al. [2011] discuss a retrospective test of rapid earthquake detection using triggers observed by a QCN aftershock deployment following the 2010 M8.8 Maule, Chile earthquake. And, the observed peak ground accelerations (PGA) could be integrated into real-time, high-resolution maps of shaking intensity, e.g. ShakeMap [Wald et al. 1999a]. Dense observations improve our understanding of how ground motions vary over small spatial scales $(<5 \mathrm{~km})$ and provide fundamental information about wave propagation through complex geologic material. Evans et al. [2005] concluded that station densities should exceed one station per $1 \mathrm{~km}^{2}$ to produce coherent ground-motion maps capable of resolving realistic variations in ground motions such as those observed in affected urban areas.

In order to utilize the QCN data in the applications mentioned above it is important to first verify that the data collected in a typical deployment provide reliable records of ground motion. Here, we compare aftershock data collected by traditional GeoNet strong-motion stations and QCN stations that were deployed following September 3, 2010, Mw 7.1 Darfield, New Zealand, earthquake [Gledhill et al. 2011]. We analyze peak ground-motion measurements collected by strong-motion stations installed in the city of Christchurch and the surrounding region to assess whether the RMS scatter in the observations are comparable. Then, we examine data from a small-scale array of six QCN stations installed within $1 \mathrm{~km}$ of a GeoNet station to compare full waveform characteristics and response spectra.

\section{Strong-motion data}

We use data recorded by 33 GeoNet strong-motion stations located near Christchurch, within the study region (Figure 1). These stations are part of the National Strong Motion (network code: SM) and Canterbury Regional Strong Motion (network code: SC) networks. The strong-motion stations include accelerometers installed inside structures as well as free-field sensors; the main instrument types include Kinemetrics Etna and Canterbury Seismic Instruments (CSI) CUSP-3 and CUSP-M accelerographs. While there are also 


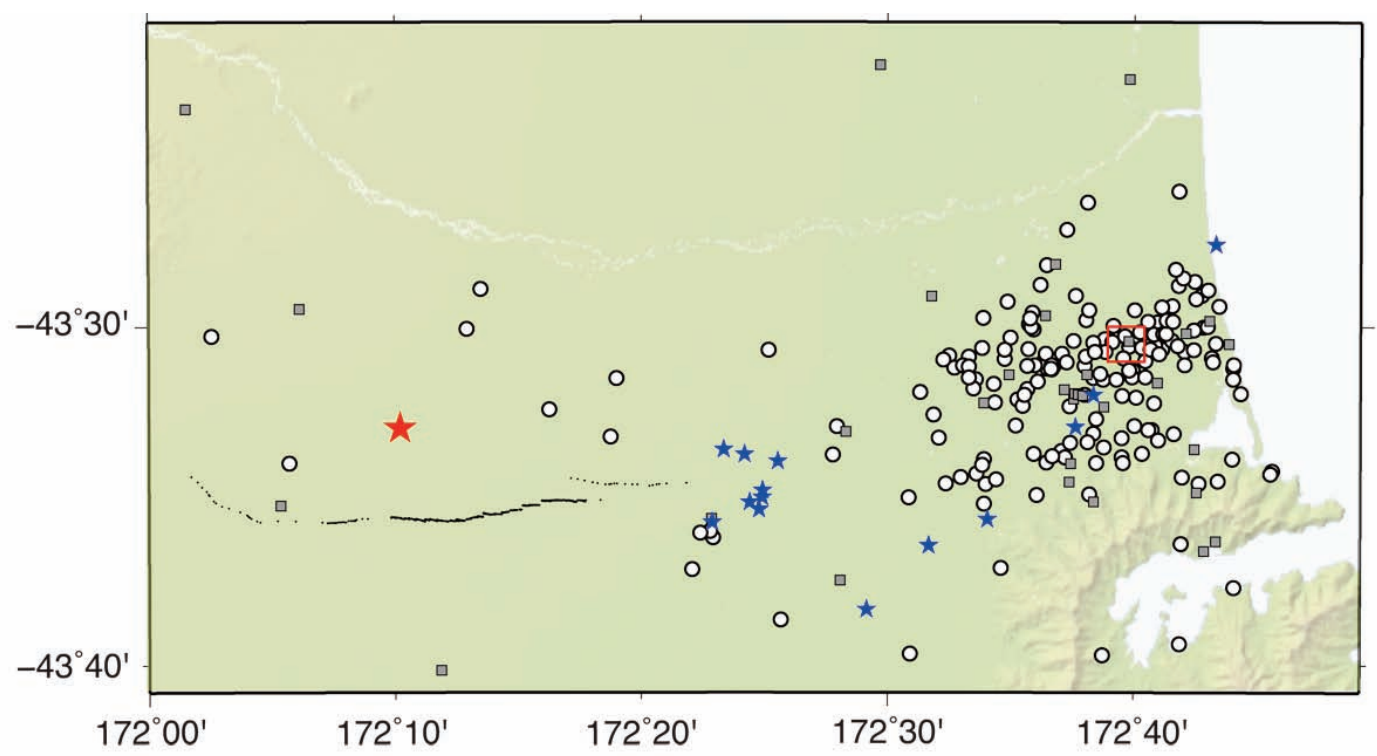

Figure 1. Map of the study area showing QCN (circles) and GeoNet (squares) station locations. Small blue stars indicate M $\geq 4.5$ earthquakes that occurred between September 15, 2010, and January 31, 2011, used in this study (Table 1) and large red star indicates the epicenter of the September 3, 2010, M7.1 Darfield mainshock. Red box indicates the zoom region shown in Figure 4.

\begin{tabular}{cccccccccccccc}
\hline Event ID & Year & Day & Hour & Min & Sec & Lat & Lon & Depth & Mag & GeoNet & QCN \\
\hline 3373925 & 2010 & 260 & 22 & 3 & 47.703 & -43.5962 & 172.3814 & 7.28 & 4.6 & 12 & 78 \\
3374803 & 2010 & 262 & 12 & 30 & 3.627 & -43.5602 & 172.3892 & 8.71 & 4.5 & 17 & 130 \\
3376639 & 2010 & 265 & 18 & 22 & 26.236 & -43.5660 & 172.4258 & 9.12 & 4.5 & 13 & 131 \\
3382676 & 2010 & 277 & 9 & 21 & 50.283 & -43.5627 & 172.4031 & 10.33 & 5.2 & 24 & 120 \\
3388384 & 2010 & 286 & 3 & 42 & 30.338 & -43.5899 & 172.4131 & 10.35 & 5.1 & 21 & 123 \\
3389582 & 2010 & 288 & 9 & 31 & 40.549 & -43.6390 & 172.4859 & 7.91 & 4.7 & 21 & 120 \\
3391440 & 2010 & 291 & 22 & 32 & 15.901 & -43.5946 & 172.5676 & 5.00 & 5.1 & 19 & 44 \\
3394581 & 2010 & 297 & 2 & 13 & 29.396 & -43.4594 & 172.7221 & 9.12 & 4.7 & 12 & 42 \\
3400620 & 2010 & 305 & 6 & 19 & 55.764 & -43.5862 & 172.4068 & 8.05 & 4.6 & 15 \\
3403219 & 2010 & 310 & 13 & 52 & 3.665 & -43.2113 & 172.0630 & 8.72 & 4.6 & 4 \\
3406713 & 2010 & 317 & 12 & 34 & 6.907 & -43.5805 & 172.4154 & 10.39 & 4.8 & 23 \\
3407078 & 2010 & 318 & 6 & 21 & 5.496 & -43.5838 & 172.4153 & 10.70 & 4.8 & 21 \\
3436956 & 2010 & 359 & 13 & 32 & 9.924 & -43.5335 & 172.6393 & 6.66 & 4.6 & 3 \\
3437105 & 2010 & 359 & 21 & 30 & 15.952 & -43.5493 & 172.6271 & 5.12 & 4.9 & 21 \\
3450113 & 2011 & 19 & 17 & 3 & 20.828 & -43.6076 & 172.5279 & 5.00 & 5.1 & 22 & 25 \\
\hline
\end{tabular}

Table 1. $M \geq 4.5$ Earthquakes: September 15, 2010, to January 31, 2011.

several building arrays deployed in Christchurch, here we include only the stations that are located on the ground floor of structures or free field installations. Sensors are installed in a range of building types from small sheds to large, multistory structures. These sensors are generally bolted either to a concrete floor or the foundation of the building. Data are recorded in triggered mode with 5-20 seconds preevent memory at 200 samples per second.

192 QCN sensors were installed in the Christchurch region following the September 3, 2010, $M_{w} 7.1$ Darfield mainshock to augment the existing strong-motion networks as part of a rapid aftershock mobilization project (RAMP) (Figure 1). The sensors installed were CodeMercenaries JoyWarrior JWF14F8 triaxial accelerometers, a 14-bit sensor that connects via USB to a computer. During the RAMP, all stations recorded continuous waveform data that were transferred to a central server every 10 minutes; in addition, stations sent real-time trigger information when significant ground motion was detected. Approximately 140 sensors were distributed in the urban sections of Christchurch region 


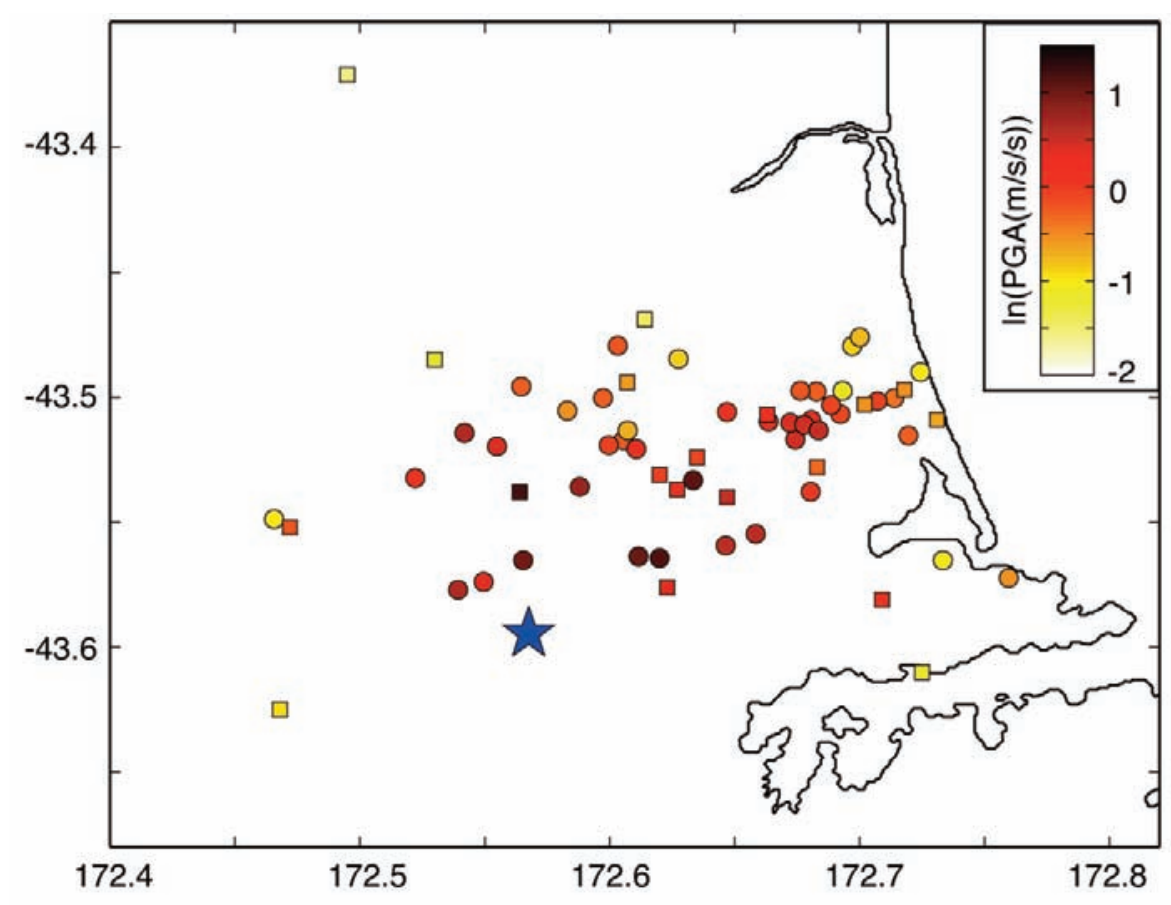

Figure 2. Peak horizontal ground acceleration $\left(\mathrm{PGA}_{\mathrm{H}}\right)$ recorded by QCN (circles) and GeoNet (squares) stations during a M5.1 aftershock on October 18,2010 (blue star). The stations are colored by observed PGA. Note that a few $(<3)$ of the QCN stations have IP-based locations that are not very accurate. We included those data here for completeness; although the location quality is included in the metadata so the data could be excluded.

with station spacing of approximately $1.6 \mathrm{~km}^{2}$. The remaining stations were installed outside of the main city limits at greater station spacing.

The QCN sensors were installed in homes, schools, and businesses of participants who volunteered to host a sensor. Almost all QCN sensors were installed on the ground floor of the building and, in some cases, sensors were placed in arrays around existing GeoNet stations. Basic information about the building, including building type (wood frame, steel, concrete, brick) and the extent of damage, if any, suffered during the M7.1 mainshock was collected at the time of installation. Sensors are typically securely fastened onto the floor of a building using either screws, glue, or tape and are located within approximately $5 \mathrm{~m}$ of a desktop computer. Sensor hosts were required to agree to at least a three-month hosting period. Following those three months, many of the temporary stations were removed; by February 2011, approximately 40-50 QCN stations remained in the Christchurch region and the removed sensors were returned to GNS Science for deployment in other regions. The participant's computer must be on to monitor the sensor and we don't require participants to modify their computer usage in order to participate in the project (e.g. leave the computer on 24 hours per day). Therefore, roughly $50 \%$ of the stations are monitoring and reporting data at any given time in a typical deployment [Chung et al. 2011].

Using data recorded by the GeoNet and QCN stations, we examine aftershocks recorded between September 15, 2010 and January 31, 2011. QCN stations recorded earthquakes as small as M2.6 locally, but these events tend to have poor signal- to-noise ratios. We limit our analysis to $M \geq 4.5$ earthquakes, which are well recorded by both networks. Within the study area and time period of interest, fifteen earthquakes occurred ranging in size from M4.55 to M5.15 (Figure 1; Table 1). Here, we compare the data recorded by the GeoNet and QCN stations to determine if QCN data provide reliable records of ground motion.

\section{Comparison of peak ground motion}

Peak ground motions recorded by strong-motion stations can be used to determine earthquake magnitude [e.g. Campbell 1981, Wu et al. 1998], map shaking intensities [e.g. Wald et al. 1999a, Wu et al. 2003], and to examine the response of structures [e.g. Nigam and Jennings 1969, Wald et al. 1999b, Wu et al. 2004]. Thus, it is important to first examine whether QCN stations provide reliable observations of peak ground acceleration, velocity, and displacement. Accelerograms are integrated to velocity, and then velocity time series are integrated to displacement. For all traces, the mean is removed, a $5 \%$ taper is applied, and accelerograms are high-pass filtered at $1 \mathrm{~Hz}$ before data are integrated. The static displacements at very low frequencies are expected to be negligible due to the small seismic moments of the earthquakes examined. Peak ground motion is defined here to be the maximum acceleration, velocity, or displacement that is observed within two minutes of the earthquake origin time.

We examine the peak ground motions recorded during a M5.1 earthquake that occurred on October 18, 2011 (Event ID: 3391440; Table 1). The aftershock was recorded by 19 

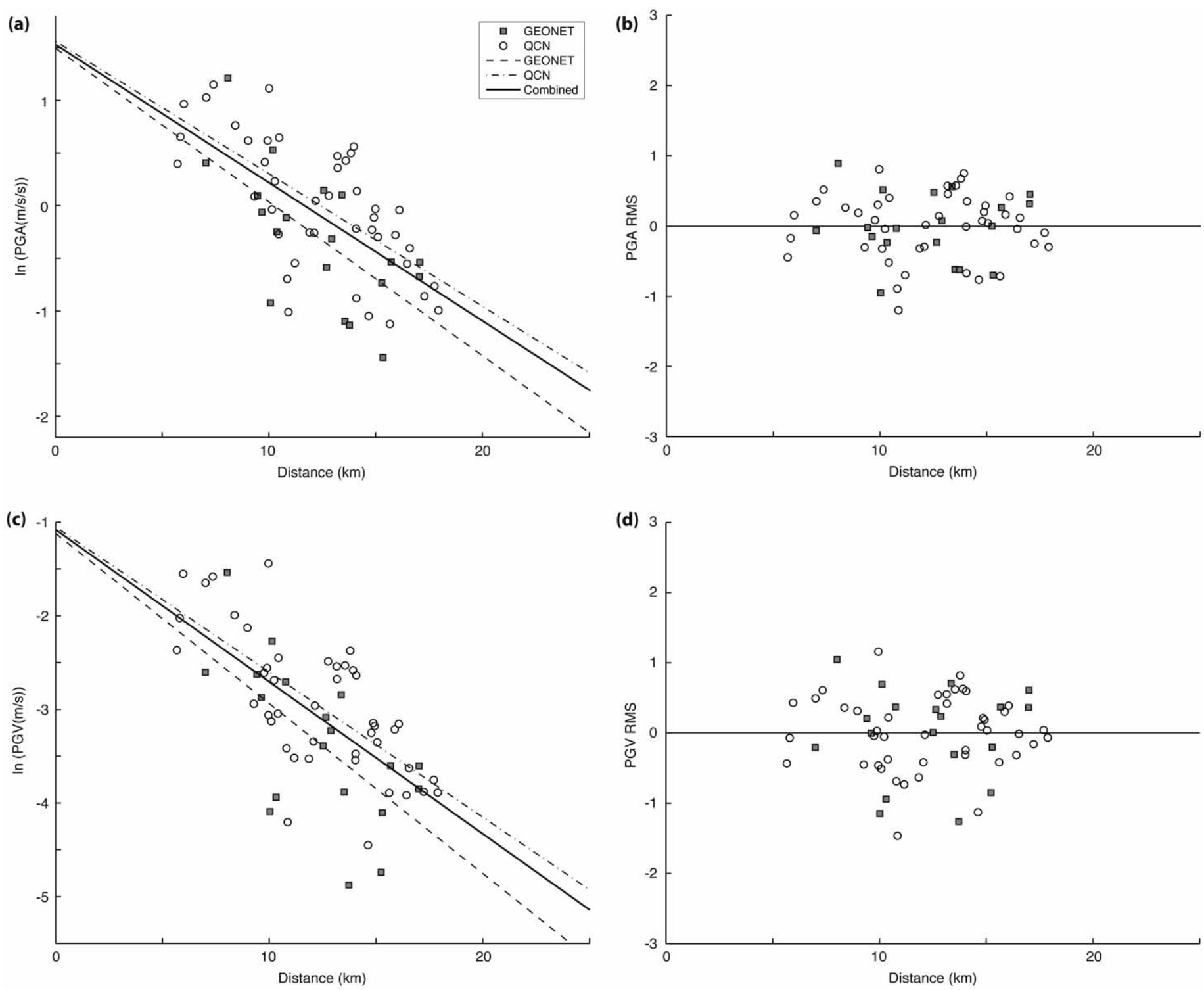

Figure 3. (a) $\mathrm{PGA}_{\mathrm{H}}$ versus distance observed on QCN (circles) and GeoNet (squares) for the October 18, 2010, M5.1 aftershock. Dashed line shows the

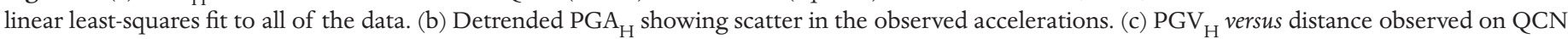
(circles) and GeoNet (squares) for the same event shown in (a) (d) Detrended PGV ${ }_{\mathrm{H}}$ showing scatter in the observed velocities. Average RMS scatter is given in Table 2.

GeoNet and 44 QCN stations located within $25 \mathrm{~km}$ of the hypocenter. Figure 2 shows the spatial distribution of observed peak horizontal acceleration $\left(\mathrm{PGA}_{\mathrm{H}}\right)$ across the city of Christchurch and outlying regions for the M5.1 aftershock. PGA $_{\mathrm{H}}$ is spatially variable, but with a clear decay in amplitude with distance as expected. In general, closely located GeoNet and QCN stations have similar reported $\mathrm{PGA}_{\mathrm{H}}$. To further examine the ground-motion variation, we plot the peak horizontal acceleration and velocity $\left(\mathrm{PGA}_{\mathrm{H}}\right.$ and $\mathrm{PGV}_{\mathrm{H}}$ ) versus distance for the the October 18, 2011 M5.1 aftershock (Figure 3a). The observed ground motions at GeoNet and QCN stations have comparable amplitudes at a given distance from the earthquake hypocenter; although the QCN accelerations and velocities are slightly higher, on average, than the GeoNet ground motions. The observed $\ln \left(\mathrm{PGA}_{\mathrm{H}}\right)$ and $\ln \left(\mathrm{PGV}_{\mathrm{H}}\right)$ versus distance are fit to a leastsquares linear trend determined for the QCN and GeoNet datasets, as well as for both datasets combined. We then detrend the observed $\mathrm{PGA}_{\mathrm{H}}$ and $\mathrm{PGV}_{\mathrm{H}}$ to compare the scatter in observed ground motions (Figure $3 \mathrm{~b}$ ). The number of GeoNet and QCN observations and their RMS scatter are given in Table 2. RMS values are slightly lower for QCN data, but this difference is not significant. Local variation in $\mathrm{PGA}_{\mathrm{H}}$ can reflect either spurious effects related to the instrumentation or real variation related to the source, path, or site conditions.

\begin{tabular}{cccc}
\hline Network & \# Obs & PGA RMS & PGV RMS \\
\hline GeoNet & 19 & 0.475 & 0.638 \\
QCN & 44 & 0.466 & 0.518 \\
\hline
\end{tabular}

Table 2. RMS scatter for event 3391440. 


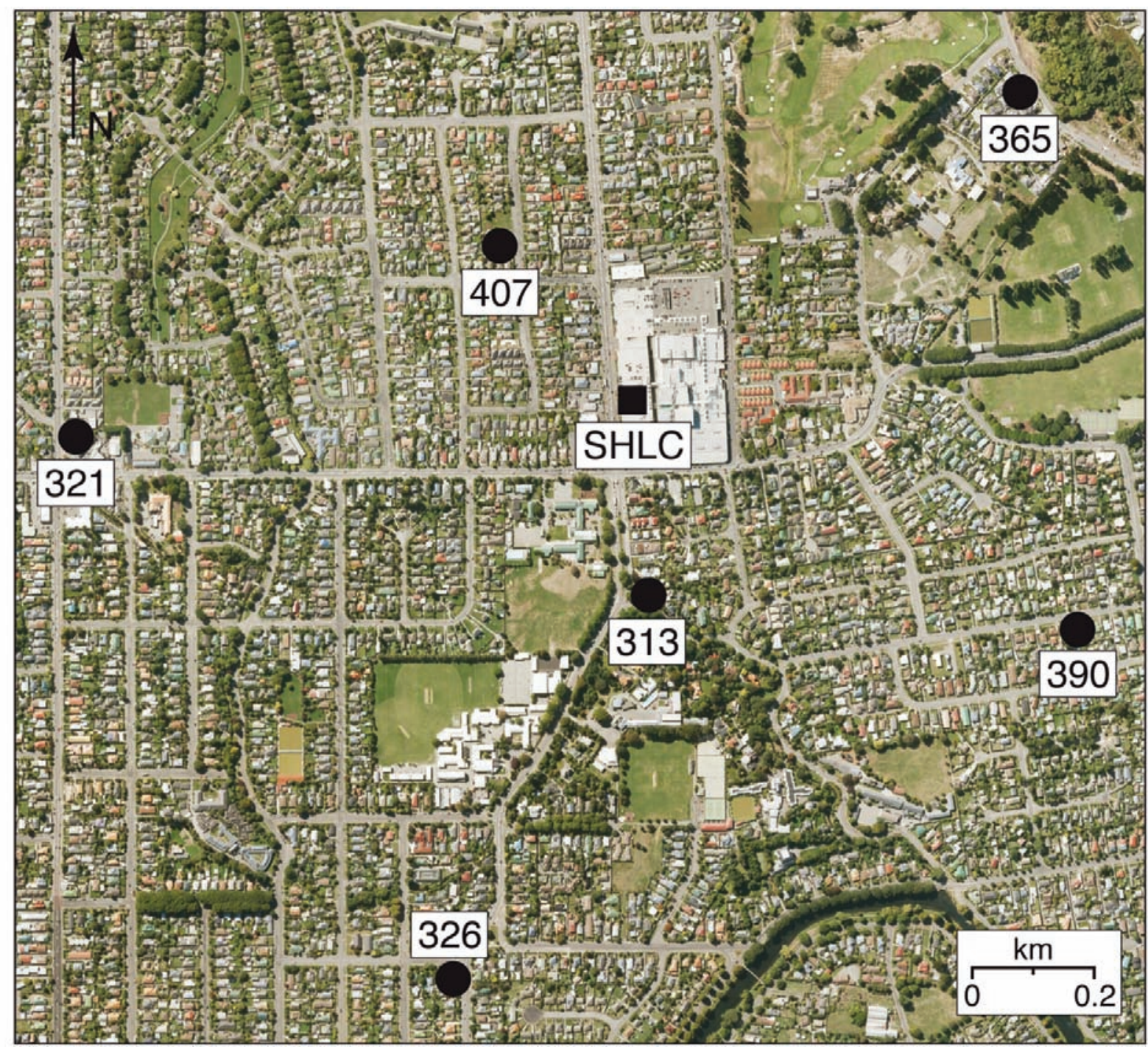

Figure 4. Map of the small-scale array of six QCN stations (circles) installed near the GeoNet station SHLC (square). The location of the map is shown in Figure 1. Additional information about each of the stations is given in Table 3.

\begin{tabular}{cccccl}
\hline Network & Station & Latitude & Longitude & Dist. (m) & Installation description \\
\hline GeoNet & SHLC & -43.507 & 172.663 & N/A & Ground floor, Shirley Library, single story, commercial \\
QCN & 407 & -43.505 & 172.661 & 318 & Ground floor, wood construction, residence \\
QCN & 313 & -43.510 & 172.664 & 319 & Ground floor, wood construction, residence \\
QCN & 365 & -43.503 & 172.671 & 817 & Ground floor, brick with wood frame construction, residence \\
QCN & 390 & -43.510 & 172.672 & 827 & Ground floor, brick construction with elevated floor, residence \\
QCN & 321 & -43.508 & 172.652 & 886 & Ground floor, concrete, commercial \\
QCN & 326 & -43.515 & 172.660 & 982 & Ground floor, wood frame on concrete pile, residence \\
\hline
\end{tabular}

Table 3. Location and installation data for the QCN array near the GeoNet station SHLC.

\section{Small-scale array comparison}

At the time of the RAMP deployment, several QCN stations were installed within $1 \mathrm{~km}$ of existing GeoNet stations. We examine records from an array of six QCN stations installed near GeoNet station SHLC, located in the Christchurch suburb of Shirley (Figure 4). All of the QCN stations were located between $0.3 \mathrm{~km}$ and $1 \mathrm{~km}$ away from station SHLC.
SHLC is installed on the ground floor of the Shirley Library, which is located in a single story building constructed in 1996. The six QCN stations were installed primarily in singlefamily residences constructed of either wood or brick (Table 3). At the time of station installation any damage related to the September 3, 2010, M7.1 Darfield mainshock was noted; these residences reported little to no structural damage. 


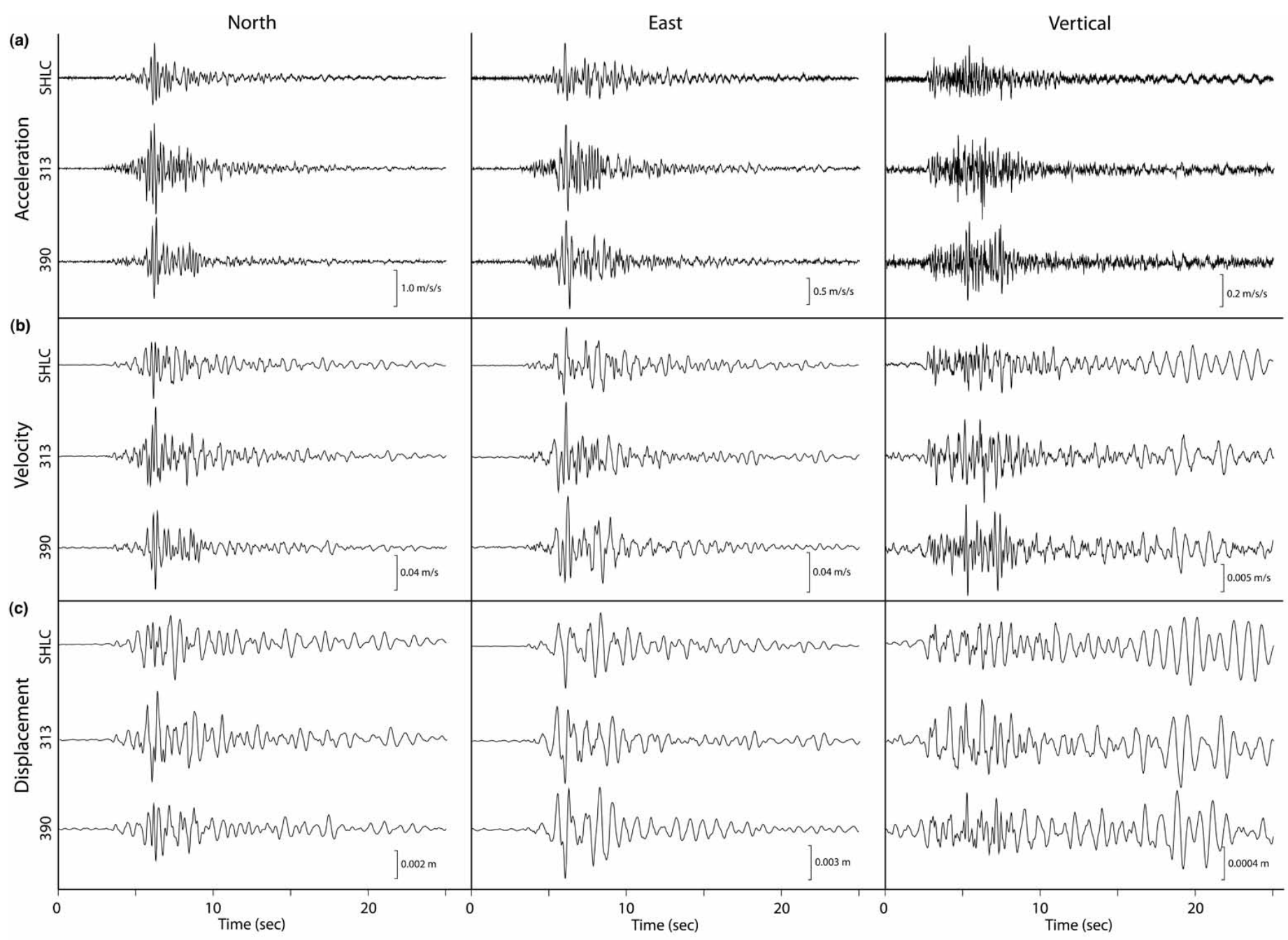

Figure 5. (a) Acceleration, (b) velocity, and (c) displacement time series for the North-South, East-West, and vertical components for stations SHLC, 313, and 390. Note that the vertical component ground motions are approximately one order of magnitude smaller than the horizontal ground motions.

Figure 5 shows acceleration, velocity, and displacement records from one GeoNet and the two closest QCN stations that recorded the October 18, 2011, M5.1 aftershock. Acceleration records are integrated to recover velocity and displacement time series, as outlined in the section above. Acceleration, velocity, and displacement waveforms are qualitatively similar in amplitude and frequency content. Some small-scale variability exists, with QCN stations 313 and 390 reporting somewhat higher accelerations than observed at GeoNet station SHLC (Figure 5). We note that the vertical displacement records of all three stations are noisy and include spurious signals after the main P-wave and S-wave phases. This noise is likely because the vertical accelerations are approximately an order of magnitude lower than the horizontal accelerations. The displacement records of the lower-resolution QCN sensors are not obviously degraded compared to the GeoNet SHLC displacement record.

Next, we compare the response spectra computed for SHLC with closely located QCN stations in the small-scale array; the response spectrum is an important metric in engineering applications to estimate effects of earthquakes on the built environment [e.g. Nigam and Jennings 1969,
Campbell and Bozorgnia 2008] and to explore the spatial variability in ground motions [e.g. Field and Hough 1997]. We compute the pseudo acceleration response spectra at each station in the small-scale array for four earthquakes (Events 3374803, 3376639, 3382676, and 3388384, see Table 1) recorded by at least 4 of the $6 \mathrm{QCN}$ stations in the array. Response spectra were computed for periods between 0.05 and 20 seconds, with $5 \%$ critical damping, for 15 -second time series segments starting one second before the P-wave arrival and extending well into the $\mathrm{S}$-wave coda. For each event, we compare the response spectra at each station, averaged over the two horizontal components (Figure 6). A simple gain correction was applied to the data but full instrument response corrections were not applied. The instrument responses of the QCN stations are unknown, but the response is expected to be flat in the frequency range examined [e.g. Holland et al. 2003, Hons et al. 2008, Zhao and Xiong 2009]. While there is some variation between events, the horizontal component response spectra for all stations tend to show peak accelerations for periods between 0.1 and 5 seconds. And, when we cross-correlate the QCN response spectra with GeoNet station SHLC we find cross- 

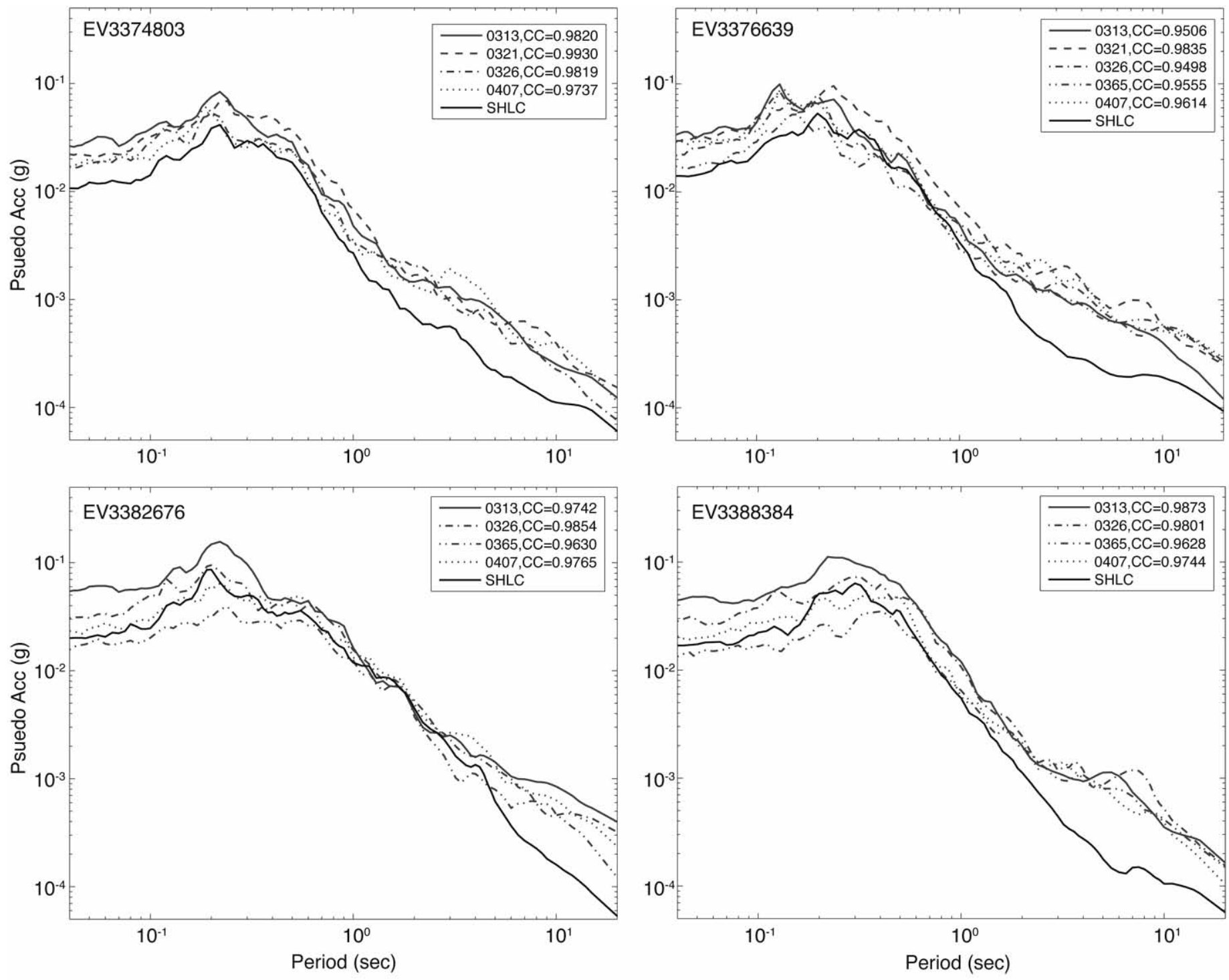

Figure 6. Horizontal component average pseudo acceleration response spectra for the GeoNet and QCN stations shown in Figure 4. Response spectra were computed for earthquakes (a) 3374803, (b) 3376639, (c) 3382676, and (d) 3388384 (See Table 1 for more information). Cross-correlation coefficients are computed between the QCN stations and GeoNet station SHLC and reported in the keys.

correlation coefficients between 0.95 and 0.99 . The pseudo accelerations appear to differ most significantly at longer periods (>10 seconds), with SHLC reporting lower accelerations than QCN stations for these periods.

\section{Discussion}

We compare peak ground motion and full waveform data recorded by existing GeoNet stations and Quake-Catcher Network stations deployed following the September 3, 2010, M7.1 Darfield earthquake. The peak ground accelerations, velocities, and displacements observed by the networks are comparable and show a clear decay with distance due to attenuation and geometric spreading. There is significant scatter in the observed ground motions at a given distance from the source, which could reflect actual variability in the ground motion, or may be due to spurious effects. Source effects (e.g. radiation pattern), propagation through different geologic material, site amplification, or building response can result highly variable ground motion. But, scatter could also be due to poor instrumentation performance (e.g. incorrect calibration or sensor malfunction) or inadequate coupling to ground motion (e.g. sensors incorrectly affixed to the ground). We find that observed PGA and PGV amplitudes and RMS scatter are comparable between the GeoNet and QCN observations, suggesting that the QCN installations provide adequate sensor performance and coupling to ground motion.

Using data from a local QCN array installed near GeoNet station SHLC, we show that the acceleration, velocity, and three-component displacement time series were comparable (Figure 5). We show the response spectra computed for QCN and GeoNet stations are also similar suggesting the data could be used to explore spatial variability in ground motions and for use in analysis of structures. And, across the seven-station array the horizontal component pseudo acceleration response spectra were 
highly correlated, with average cross-correlation coefficients of 0.94 or higher for station pairs located at distances up to $1.7 \mathrm{~km}$ apart. However, the responses diverge somewhat for periods above 10 seconds $(<0.1 \mathrm{~Hz})$ with the GeoNet station SHLC showing consistently lower spectral accelerations than QCN stations. This difference may either be the result of structural response convolved into the accelerogram, different instrument responses at these periods, or because of poor reliability of the low-resolution $\mathrm{QCN}$ sensors at lower frequencies. Further study is needed to determine which of these factors has the largest influence on the computed response spectra.

We have shown that the Quake-Catcher Network stations perform comparably to the traditional GeoNet strong motion stations in a large-scale aftershock deployment in Christchurch, New Zealand following the M7.1 Darfield mainshock. By utilizing MEMS sensors and distributed computing techniques it is possible to provide reliable records of strong ground motion at greatly increased station densities.

\section{Data and sharing resources}

- GeoNet strong-motion time-series data used in this study are available at ftp:/ / ftp.geonet.org.nz/strong/processed/ Proc. 'Vol1' data was used in this analysis.

- QCN strong-motion data are available by request (http:// qcn.stanford.edu, ecochran@usgs.gov).

- QCN seismic monitoring software is run on the Berkeley Open Infrastructure for Network Computing (BOINC) (http:/ / boinc.berkeley.edu) [Anderson 2004].

- Data processing was completed using Seismic Analysis Code (SAC) version 101.1 (www.iris.edu/software/sac) [Goldstein et al. 2003, Goldstein and Snoke 2005].

- Some data analysis was completed using Mathworks Matlab version 7.9.0 (R2009b).

- Figure 1 was generated using Generic Mapping Tools version 4.2.1 (www.soest.hawaii.edu/gmt) [Wessel and Smith 1998] with topographic data from Geographx (www. geographx.co.nz).

- Figure 5 was generated using Google Earth version 6.0 .3 (earth.google.com).

\section{References}

Anderson, D.P. (2004). BOINC: A system for public-resource computing and storage, In: Proceedings of the Fifth IEEE/ ACM International Workshop on Grid Computing, 4-10.

Campbell, K.W. (1981). Near-source attenuation of peak horizontal acceleration, B. Seismol. Soc. Am., 71 (6), 20392070.

Campbell, K.W., and Y. Bozorgnia (2008). NGA ground motion model for the geometric mean horizontal component of PGA, PGV, PGD and 5\% damped linear elastic response spectra for periods ranging from 0.01 to $10 \mathrm{~s}$, Earthq. Spectra, 24, 139-171.

Chung, A.I., C. Neighbors, A. Belmonte, M. Miller, H.H. Sepulveda, C. Christensen, R.S. Jakka, E.S. Cochran and J.F. Lawrence (2011). The Quake-Catcher Network Rapid Aftershock Mobilization Program Following the 2010 M 8.8 Maule, Chile Earthquake, Seismol. Res. Lett., 82 (4), 526-532.

Cochran, E.S., J.F. Lawrence, C. Christensen and R. Jakka (2009a). The Quake-Catcher Network: Citizen science expanding seismic horizons, Seismol. Res. Lett., 80, 26-30.

Cochran, E.S., J.F. Lawrence, C. Christensen and A.I. Chung (2009b). A novel strong-motion seismic network for community participation in earthquake monitoring, IEEE Instru. Meas. Mag., 12 (6), 8-15.

Evans, J.R., R.H. Hamstra Jr., C. Kundig, P. Camina and J.A. Rogers (2005). TREMOR: A wireless MEMS accelerograph for dense arrays, Earthq. Spectra, 21 (1), 91-124.

Field, E.H. and S.E. Hough (1997). The variability of PSV response spectra across a dense array deployed during the Northridge aftershock sequence, Earthq. Spectra, 13 (2), 243-257.

Fleming, K., M. Picozzi, C. Milkereit, F. Kuhnlenz, B. Lichtblau, J. Fischer, C. Zulfikar, O. Ozel and the SAFER and EDIM working groups (2009). The self-organizing seismic early warning information network (SOSEWIN), Seismol. Res. Lett., 80 (5), 755-771.

Frassetto, A., T.J. Owens and P. Crotwell (2003). Evaluating the Network Time Protocol (NTP) for timing in the South Carolina Earth Physics Project (SCEPP), Seismol. Res. Lett., 74, 649-652.

Gledhill, K., J. Ristau, M. Reyners, B. Fry and C. Holden (2011). The Darfield (Canterbury, New Zealand) Mw 7.1 earthquake of September 2010: A preliminary seismological report, Seismol. Res. Lett., 82, 378-386.

Goldstein, P., D. Dodge, M. Firpo and L. Minner (2003). SAC2000: Signal processing and analysis tools for seismologists and engineers, In: W.H.K. Lee, H. Kanamori, P.C. Jennings and C. Kisslinger (eds.), The IASPEI International Handbook of Earthquake and Engineering Seismology, Academic Press, London.

Goldstein, P. and A. Snoke (2005). SAC Availability for the IRIS Community, Incorporated Institutions for Seismology Data Management Center Electronic Newsletter.

Holland, A. (2003). Earthquake data recorded by the MEMS accelerometer: Field testing in Idaho, Seismol. Res. Lett., 74 (1), 20-26.

Hons, M.S., R.R. Stewart, D.C. Lawton and M.B. Bertram (2008). Field data comparisons of MEMS accelerometers and analog geophones, The Leading Edge, 27 (7), 896-903.

Kanamori, H. (2005). Real-time seismology and earthquake damage mitigation, Annu. Rev. Earth Pl. Sc., 33, 195-214. Mills, D.L. (1990). On the accuracy and stability of clocks 
synchronized by the Network Time Protocol in the Internet system, ACM Computer Communication Review, 20, 65-75.

Nigam, N.C. and P.C. Jennings (1969). Calculation of response spectra from strong-motion earthquake records, B. Seismol. Soc. Am., 59, 909-922.

Picozzi, M., C. Milkereit, C. Zulfikar, K. Fleming, R. Ditommaso, M. Erdik, J. Zschau, J. Fischer, E. Safak, O. Ozel, and N. Apaydin (2009). Wireless technologies fort he monitoring of strategic civil infrastructures: an ambient vibration test on the Fatih Sultan Mehmet suspension bridge in Istanbul, Turkey, B. Earthq. Eng., 8 (3), 671-691; doi: $10.1007 /$ s10518-009-9132-7.

Wald, D.J., V. Quitoriano, T.H. Heaton, H. Kanamori, C.W. Scrivner and C.B. Worden (1999a). TriNet "ShakeMaps": rapid generation of peak ground motion and intensity maps for earthquakes in southern California, Earthq. Spectra, 15, 537-555.

Wald, D.J., V. Quitoriano, T.H. Heaton and H. Kanamori (1999b). Relationships between peak ground acceleration, peak ground velocity and Modified Mercalli Intensity in California, Earthq. Spectra, 15, 557-564.

Wessel, P. and W.H.F. Smith (1998). New, improved version of the Generic Mapping Tools released, Eos Trans. AGU, $79,579$.

Wu, Y.-M., T.-C. Shin and Y-B. Tsai (1998). Quick and reliable determination of magnitude for seismic early warning, B. Seismol. Soc. Am., 88 (5), 1254-1259.

Wu, Y.-M., T.-L. Teng, T.-C. Shin and N.-C. Hsiao (2003), Relationship between Peak Ground Acceleration, Peak Ground Velocity, and Intensity in Taiwan, B. Seismol. Soc. Am., 93, 386-396.

Wu, Y.-M., N.-C. Hsiao and T.-L. Teng (2004). Relationships between strong ground motion peak values and seismic loss during the 1999 Chi-Chi, Taiwan earthquake, Nat. Hazards, 32, 357-373.

Zhao, M. and X. Xiong (2009). A new MEMS accelerometer applied in civil engineering and its calibration test, In: Ninth International Conference on Electronic Measurements and Instruments (ICEMI '09), 2:122-2:125.

\footnotetext{
${ }^{\star}$ Corresponding author: Elizabeth S. Cochran,

University of California, Riverside, USA; now at: U.S. Geological Survey, USA; email: ecochran@usgs.gov.

(C) 2011 by the Istituto Nazionale di Geofisica e Vulcanologia. All rights reserved.
} 